\title{
Processos avaliativos e/na educação matemática: um estudo sobre o Programa Escola Ativa
}

\author{
Evaluation processes and/in mathematics education: \\ a study about the Escola Ativa Program
}

\author{
Procesos evaluativos y/en la educación matemática: \\ un estudio sobre el Programa Escola Ativa
}

\author{
FERNANDA WANDERER* \\ GELSA KNIJNIK**
}

\begin{abstract}
RESUMO - O artigo examina o Programa Escola Ativa (PEA), endereçado às escolas multisseriadas do campo do país, enfocando os processos avaliativos ali presentes, no que diz respeito à educação matemática. Os aportes teóricos que dão sustentação ao estudo encontram-se nas formulações de Michel Foucault, em especial as que dizem respeito às práticas disciplinares e às tecnologias do eu. O material de pesquisa está circunscrito aos documentos do PEA direcionados aos professores. O exercício analítico sobre esse material(realizado na perspectiva da análise do discurso foucaultiano),possibilitou concluir que, no PEA, a avaliação: a) é concebida como um mecanismo de disciplinamento dos corpos e dos saberes que opera em um continuum e está presente em todas as etapas da aprendizagem da matemática; b) atua sobre os sujeitos escolares mediante diferentes práticas avaliativas; c) na área da matemática, tem como um de seus eixos principais a análise do erro do aluno.

Palavras-chave - Educação matemática. Processos avaliativos. Programa Escola Ativa. Escolas multisseriadas do campo. Foucault

ABSTRACT - The paper discusses the Escola Ativa Program (in Portuguese, Programa Escola Ativa - PEA), ad dressed to Brazilian multigrade peasant schools. It is focused in the evaluation processes concerning mathematics education. The study theoretical framework is built through Michel Foucault's theorizations, specifically those related to disciplinary practices and technologies of the self. Data are composed by PEA teachers' documents. The analytical exercise (done from the perspective of the Foucault's discourse analysis) made possible to conclude that in PEA, the evaluation: a) is conceived as a disciplinary bodies and know ledges mechanism that operates in a continuum and exists in every learn ingma the matics phase; acts over the school subjects through different evaluation practices; c) in the area of mathematics, it has as one of its main axis the analysis of the student's error.
\end{abstract}

Keywords - Mathematics education. Evaluation processes. Escola Ativa Program. Peasant multigrade schools. Foucault.

RESUMEN - El artículo analiza el Programa Escola Ativa (PEA) destinado a las escuelas rurales multigrado de Brazil, poniendo atención a los procesos evaluativos allí presentes, en lo que se refiere a la educación matemática. Los aportes teóricos que embazan el estudio están situados en las formulaciones de Michel Foucault, en especial las que se conectan a las prácticas disciplinares y a las tecnologías del yo. El material de pesquisa se circunscribe a documentos del PEA direccionados a los maestros. El ejercicio analítico sobre el material (realizado en la perspectiva del análisis del discurso foucaultiano) posibilitó concluir que, en el PEA, la evaluación: a) es concebida como un mecanismo de disciplinamiento de los cuerpos y de los saberes que opera en un continuum y está presente en todas las etapas del aprendizaje de las matemáticas; b) actúa sobre los sujetos escolares a través de diferentes prácticas evaluativas; c) en el área de las matemáticas, tiene como uno de sus ejes principales el análisis del error del alumno.

Palabras-claves - Educación Matemática. Procesos evaluativos. Programa Escuela Activa. Escuelas rurales multigrado. Foucault.

\footnotetext{
* Doutora em Educação pela Universidade do Vale do Rio dos Sinos (São Leopoldo, RS, Brasil) e Professora na Universidade Federal do Rio Grande do Sul (Porto Alegre, RS, Brasil). E-mail: <fernandawanderer@gmail.com>.

** Doutora em Educação pela Universidade Federal do Rio Grande do Sul (Porto Alegre, RS, Brasil) e Professora na Universidade do Vale do Rio dos Sinos (São Leopoldo, RS, Brasil). E-mail: <gelsak@unisinos.br>.
} 


\section{INTRODUÇÃO}

Este artigo tem como propósito analisar os processos avaliativos presentes no Programa Escola Ativa (PEA), no âmbito da educação matemática. O Programa se constitui em uma das políticas públicas educacionais que têm sido implementadas no país em anos recentes, endereçado às escolas multisseriadas do campo. Mesmo que, a partir de 2013, o Ministério de Educação e Cultura (MEC) tenha anunciado a instauração do "Escola da Terra" (um programa cujos propósitos coincidem com os do PEA, sendo endereçado a um público mais amplo - incluindo, agora, as escolas quilombolas - e com a distribuição de novos materiais pedagógicos), ${ }^{1}$ estudos sobre o PEA mantém sua relevância. Em primeiro lugar, porque o novo programa dá continuidade (e, possivelmente substituirá) o PEA. O "Escola da Terra" encontra-se ainda em fase experimental ${ }^{2}$ e os materiais pedagógicos a serem distribuídos estão em elaboração. Nesse sentido, uma análise mais aprofundada dos documentos do PEA (iniciada em Wanderer e Knijnik (2013)) pode trazer elementos que favoreçam a conformação do novo programa.

Em segundo lugar, as ações do PEA ainda estão em curso. O Programa atendia, no início da década de 2010, mais de dez mil escolas multisseriadas do campo, ${ }^{3}$ abrangendo um conjunto de ações que envolvem a produção de materiais para alunos e professores, a promoção de cursos de formação continuada aos docentes e a implementação, em cada município participante, de um microcentro que oportuniza a criação de grupos de estudos. Os materiais distribuídos às escolas são endereçados aos alunos (Cadernos de ensino e aprendizagem de diferentes áreas do currículo escolar) e aos professores (um Caderno de orientações pedagógicas para formação de educadoras e educadores e outros com foco nas diferentes áreas do currículo). Além disso, o programa envia kits com materiais para uso em sala de aula (KNIJNIK e WANDERER, 2013).

Em anos recentes, a comunidade educacional tem mostrado interesse em investigar o PEA. Estudos como os Gonçalves (2009), Matos (2010), Aragão (2011), Ribeiro (2011) e Moreira (2013) apontam nessa direção. Isso se deve, entre outros fatores, por ser o PEA uma política pública implementada nas diferentes regiões do país; por envolver ações que estabelecem vínculos entre universidades, secretarias de educação estaduais e municipais, assim como escolas multisseriadas; e por promover os cursos de formação, envolvendo professores e supervisores das escolas. Na área da Educação Matemática, trabalhos sobre o PEA foram realizados por autores como Alves e Monteiro (2011), Junges (2012) e Knijnik e Wanderer (2013). Especificamente, no que se refere à avaliação da matemática escolardo PEA, há um estudo inicial realizado por Wanderer e Knijnik (2013) que se constituiu no embrião deste artigo.

$\mathrm{O}$ material de pesquisa escrutinado neste trabalho abrange os documentos disponibilizados pelo PEA aos educadores, em especial aqueles da área da matemática (BRASIL 2010a, 2010b, 2010c). Em consonância com o referencial teórico do estudo, esses documentos foram examinados desde a perspectiva da análise do discurso foucaultiana. ${ }^{4}$ Ao nos servimos dessa perspectiva, estivemos cientes de que o expresso no material precisaria ser considerado em sua exterioridade. Tratava-se de tomar o dito na sua superfície, sem que fosse submetido, por exemplo, a interpretações do tipo causa-efeito, as quais Foucault, inspirado em Nietzsche, se opôs. Tampouco caberia emitir juízos de valor sobre as orientações pedagógicas apresentadas nos documentos: essa atitude valorativa comprometeria o exercício analítico inspirado no filósofo francês que desejávamos empreender. Mais ainda: seguindo suas formulações, consideramos que tais documentos "entram em convergência com instituições e práticas, e carregam significações que podem ser comuns a toda uma época" (FOUCAULT, 2002a, p. 139). Dito de outro modo, estão na "ordem do discurso" pedagógico (brasileiro) contemporâneo. É nesse sentido que Foucault afirma ser "o sujeito uma variável, ou melhor, um conjunto de variáveis do enunciado" (DELEUZE, 2005, p. 64), isto é, não é ele que estaria na "origem" do discurso. Assim, uma análise inspirada em Foucault necessariamente "exclui a priori um sujeito da enunciação" (ibidem, p. 64), pois, para o filósofo, o a priori a ser levado em conta é o a priori histórico.

O texto está divido em três seções. A primeira consiste nesta Introdução. Na segunda seção são discutidas as principais ideias do referencial teórico utilizado, juntamente com a análise efetivada sobre o material de pesquisa. Ao optarmos por articular dois movimentos a apresentação das noções que embasam teoricamente o trabalho e a discussão do material empírico, tivemos a intenção de dar visibilidade às noções que se tornariam ferramentas de análise, mostrando, ao operar com elas, sua produtividade. Na última seção, "Considerações finais", servindo-nos das formulações de Foucault sobre a "crítica" e as de Veiga-Neto sobre a "hipercrítica", questionamos a relevância de um trabalho analítico como o aqui empreendido.

\section{REFERENCIAL TEÓRICO DO ESTUDO E RESULTADOS}

A área da avaliação tem ocupado um lugar de destaque literatura educacional, principalmente em tempos mais recentes, devido às avaliações de larga escala que têm 
sido feitas em âmbito nacional e internacional, através de exames, tais como a Prova Brasil (MOTA, 2012; ANDRADE, 2011) e o PISA (BECKER, 2010). Como mostram os estudos de Petronzelli (2013), Becker (2010) e Carvalho (2009), tais avaliações estão em consonância com as orientações da OCDE, formuladas com base em uma lógica neoliberal e seus resultados vêm sendo utilizados como parâmetros para a formulação de políticas públicas. Barriga (1993) é contundente em sua análise sobre como, ao longo dos tempos, o exame foi perdendo suas dimensões pedagógicas e metodológicas, estando, na contemporaneidade, alinhado com o que o autor denomina "corte neoliberal", acarretando que problemas sociais se transformem em problemas técnicos, problemas metodológicos em problemas de rendimento e problemas teóricos da educação em problemas técnicos de avaliação (ibidem, p. 4).

No âmbito da educação matemática, artigos como os de Machado (2010), Buriasco e Soares (2007), no país, assim como os de Morgan (1999) e Stacey e Wiliam (2013) tematizam o pouco impacto que tem os exames que sustentam as avaliações de larga escala para a melhoria do ensino e aprendizagem da matemática, e, com isso, a qualificação do sistema educativo nacional. Suas análises mostram que apenas informar os professores com dados quantitativos sobre os erros e acertos de seus alunos nesses testes não conduz a uma reflexão mais ampla sobre a educação matemática praticada nas escolas.

No entanto, cronologicamente situados em um período anterior a esses estudos, há um amplo conjunto de trabalhos que discutem a avaliação escolar, isto é, aquela que é levada a efeito no cotidiano da sala de aula (VASCONCELOS, 2007; ESTEBAN, 2002; LUCKESI, 2005; HOFFMANN, 1996).Nesse conjunto pode-se identificar duas grandes vertentes analíticas: a primeira delas, que se ocupa da discussão dos instrumentos e procedimentos avaliativos em si mesmos, isto é, discuteos a partir de sua lógica interna. Neles, o interesse primordial é examina-los quanto à sua eficácia pedagógica no processo de aprendizagem (VASCONCELOS, 2007; LUCKESI, 2005; HOFFMANN, 1996). A segunda, enfoca a avaliação desde uma perspectiva "exterior", mostrando seus estreitos vínculos com a educação entendida como "condução de condutas" - e suas práticas disciplinares. Aqui a referência teórica central advém de Michel Foucault, como mostram os estudos Corazza (1995), Esteban (2002), Carvalho (2004) e Arnold (2006). Este artigo insere-se nessa última vertente.

Em efeito, a análise dos documentos do PEA endereçados aos docentes, quando examinados com lentes foucaultianas, evidenciou que a avaliação constitui-se em um dispositivo de disciplinamento dos corpos e saberes que se desenvolve em um continuum e está presente em todas as etapas da aprendizagem da matemática. Nos Cadernos do PEA é expresso: "Vista como processo, a avaliação não se restringe a um momento final de verificação, mas permeia toda a ação pedagógica" (BRASIL, 2010c, p. 14). "A avaliação deve ser contínua e sistemática e se realizar por meio da interpretação qualitativa da aprendizagem do aluno" (ibidem, p. 14). "O professor deve considerar os resultados obtidos em provas, exercícios e trabalhos; mas a avaliação não se esgota nesses recursos: todos os indícios e evidências demonstradas são excelentes oportunidades para perceber e considerar o desempenho e os avanços do aluno" (ibidem, p. 15). E esses "indícios e evidências" podem ser obtidos a partir do preenchimento de uma ficha composta por questões como:

\begin{abstract}
Procura resolver problemas por seus próprios meios? Usa estratégias criativas ou apenas convencionais? Faz perguntas? Justifica suas respostas? Comunica suas respostas com clareza? Participa dos trabalhos em grupo? Ajuda os outros na resolução de problemas? Contesta pontos que não compreende ou com os quais não concorda? (BRASIL, 2010c, p. 15).
\end{abstract}

Os excertos acima destacam que a avaliação deve estar presente em todos os momentos da prática pedagógica do professor, abrangendo não só os resultados das provas e trabalhos, mas as diferentes ações dos estudantes na escola. Ou seja, seguindo as recomendações dos Cadernos do PEA pode-se dizer que os conhecimentos, as atitudes e o modo de ser dos alunos passam a ser alvo do olhar constante e examinador do educador. Esta concepção de avaliação a torna um mecanismo do poder disciplinar como discutido por Michel Foucault.

Em Vigiar e Punir, Foucault (2002b) destaca que, ao longo da época clássica, houve como que uma descoberta do corpo, ou seja, este passa a ser investido pelo poder, tornando-se, assim, manipulável, modelado, treinado e obediente. Essa invenção do corpo pode ser entendida como efeito de uma série de processos (diferentes, esparsos, mínimos) que passaram a ocorrer em hospitais, no exército e também nas escolas. Podemos afirmar, então, que o corpo entra num "campo político" ou, como explica o filósofo, "as relações de poder têm alcance imediato sobre ele [corpo]; elas o investem, o marcam, o dirigem, o supliciam, sujeitam-no a trabalhos, obrigam-no a cerimônias, exigem-lhe sinais" (ibidem, p. 25).

Para o funcionamento do poder disciplinar, segundo Foucault, foi necessário o desenvolvimento de dispositivos, técnicas ou instrumentos que, pelo "jogo do olhar" (2002b, p. 143), conduzissem a efeitos de poder e, ao mesmo tempo, fossem capazes de tornar visíveis os indivíduos sobre quem tais técnicas se dirigem. Nas palavras do filósofo, "o aparelho disciplinar perfeito capacitaria um único olhar tudo ver permanente- 
mente" (ibidem, p. 146), ou seja, para o olho perfeito, nada escaparia, ele centraria em sua direção todos os demais olhares. O exame das recomendações do PEA no âmbito da avaliação da aprendizagem dos alunos permite dizer que nos atos pedagógicos das escolas multisseriadas do campo passam a ser empreendidos procedimentos que integram a avaliação da apropriação de conhecimentos - por meio de provas e trabalhos - com mecanismos de vigilância sobre as atitudes e o modo de ser dos alunos, uma vez que o professor é incitado a identificar aqueles que se comunicam com clareza, auxiliam os colegas, contestam, participam dos trabalhos em grupo e sabem fazer perguntas.

Discutindo sobre o poder disciplinar, Dreyfus e Rabinow (1995, p. 173) afirmam que a vigilância torna-se parte da produção e do controle, ou seja, "o ato de vigiar e ser vigiado será o principal meio pelo qual os indivíduos são reunidos no espaço disciplinar". Assim, da mesma forma que a vigilância opera na sala de aula - quando o professor passa a observar atentamente as atitudes e o desempenho dos alunos nas diferentes áreas do conhecimento -, um grupo de gestores (das Universidades e Secretarias Estaduais e Municipais envolvidas no PEA) é indicado para supervisionar as escolas e o trabalho realizado pelos professores, colocando em funcionamento uma observação detalhada que permite o exercício de um controle também sobre os educadores. No Projeto Base do PEA é dito que o Ministério da Educação desenvolverá um sistema de avaliação e monitoramento do Programa através do qual "serão identificados processos e resultados, realizadas comparações dos dados levantados quanto ao desempenho de alunos, professores e instituições escolares e propostos ajustes ao Programa" (BRASIL, 2010a, p. 49).Tais dados serão reunidos por assessores do Estado ou Município em "visitas técnicas às escolas, reuniões e atividades de formação" (ibidem, p. 48) com os professores. Nesse sentido, Foucault (2002b) destaca que a escola se constitui em uma máquina de exame que perpassa a dimensão pedagógica, local onde uma comparação vai sendo instalada, e que tanto os conhecimentos quanto as atitudes de professores e alunos vão sendo medidas e sancionadas.

Em efeito, apoiando-se nas discussões foucaultianas sobre o exame, Esteban (2002) destaca que a avaliação escolar, sustentada por um padrão que compara, diferencia, classifica e exclui, atua como um dos mecanismos de disciplinamento dos corpos e saberes dos escolares. "A avaliação escolar, que mantém a lógica do exame e em certa medida a amplifica, pode ser entendida como um dos métodos sociais mais suaves, (...) de manter a disciplina; um dos instrumentos capazes de atuar com intensidade e amplitude sobre o sujeito em sua totalidade" (ibidem, p. 108).
O exame, para Foucault (2002b), realiza uma inversão na visibilidade do poder, ou seja, este se torna invisível. Diferentemente do que ocorria com o poder soberano, que iluminava o dominador, com o poder disciplinar, são os súditos que passam a ser vistos e oferecidos a um poder que só se manifesta pelo olhar. Como expressa o filósofo, o que mantém o indivíduo disciplinado é o fato de poder ser visto, sendo o exame o instrumento pelo qual o poder prende os indivíduos num mecanismo de objetivação. Nesse sentido, Dreyfus e Rabinow (1995, p. 175) destacam que "agora [na sociedade disciplinar] é o poder que fica invisível e os objetos de poder - aqueles sobre os quais funciona - se tornam mais visíveis".

Além de fazer com que o poder se torne invisível, o exame estabelece a junção do saber com o poder fazendo cada individualidade entrar no campo do documentário, ou seja, os indivíduos passam a ser constantemente observados, vigiados, normalizados e, além disto, têm seus comportamentos e saberes documentados. "Os procedimentos de exame são acompanhados imediatamente de um sistema de registro intenso e de acumulação documentária" (FOUCAULT, 2002b, p. 157). Como os excertos acima mostram, esse sistema de registro e documentação está presente nas atividades do PEA. O exame, exercido pela escrita de relatórios, põe em ação duas possibilidades, segundo Foucault (2002b): o indivíduo passa a ser um objeto descritível e analisável e, ao mesmo tempo, há a formação de um sistema que permite descrever grupos, caracterizar fenômenos e também estimar a distribuição dos indivíduos numa população.

A análise do material de pesquisa mostrou, ademais, que as orientações dadas pelo Programa no que diz respeito à avaliação indicam que essa não deve ser realizada somente pelo professor, mas incluir todos os sujeitos do espaço escolar:

Para a Educação do Campo, avaliar passa a ser entendido sempre como um processo participativo e democrático, pois abrange todos os momentos, elementos e sujeitos do trabalho educativo. Assim, a avaliação se amplia ao ser entendida como parte de um processo e não como o momento final. Ela se democratiza, pois passa a incluir todos os sujeitos que estão envolvidos no contexto escolar: educadores(as), estudantes e comunidade. Inclui a avaliação de todos os integrantes do espaço escolar, das condições da escola, das condições do trabalho da(o) educadora(or), ampliando para além da relação educadora(or)educando(a) a tarefa de avaliar e ultrapassando as limitações do processo. (BRASIL, 2010b, p. 68)

E são muitos os instrumentos indicados pelos Cadernos para a prática avaliativa na escola. Para que os 
professores possam avaliar os alunos é sugerido o uso de: "fichas de acompanhamento e progresso" para registro dos resultados das avaliações dos estudantes, exercícios referentes ao conteúdo desenvolvido nas unidades dos Cadernos das diferentes áreas do conhecimento, portfólio, seminários, observações dos trabalhos dos alunos e atividades de recuperação. Mas não só os professores, os alunos também são convocados a realizarem a avaliação de seus colegas por meio da análise minuciosa do caderno. "Após observar o caderno do colega, é bom deixar um bilhete com observações como: o que aprendi olhando seu caderno; o que mais gostei no seu caderno; seu caderno deu-me ótima ideia; o que você pode melhorar no seu caderno" (BRASIL, 2010b, p. 7). Além disso, a auto avaliação é incentivada, pois "quando bem conduzida, é um instrumento valioso para tornar o aluno consciente de suas possibilidades, de suas dificuldades e de seus progressos" (ibidem, p. 16). E essa "boa condução" é explicitada: "Após a realização de algumas atividades, é interessante propiciar aos alunos momentos de reflexão sobre seu desempenho, focalizando seu nível de compreensão e participação de tarefas, o porquê do erro e/ou do acerto (ibidem, p. 16)".

Aqui nos interessa destacar o quanto a prática da auto avaliação, como indicada pelos documentos do PEA, se constitui em uma experiência que fabrica modos de ser, no sentido discutido por Foucault (2001b).Na introdução de seu livro História da Sexualidade 2 - o uso dos prazeres, o filósofo assinala que seu interesse, ao estudar a história da sexualidade, estaria centrado na análise das maneiras pelas quais, nas sociedades ocidentais modernas, se constitui uma experiência através da qual os indivíduos passam a se reconhecer como sujeitos. Em seu entendimento, a experiência é "a correlação, numa cultura, entre campos de saber, tipos de normatividade e formas de subjetividade" (ibidem, p. 10). O filósofo (ibidem, p. 11) salienta seu interesse em estudar as práticas através das quais os indivíduos foram guiados a "prestar atenção a eles próprios, a se decifrar, a se reconhecer e se confessar como sujeitos", estabelecendo uma certa relação "de si para consigo" que lhes permite descobrir "a verdade de seu ser". Tais estudos têm como elemento central de sua teorização as "tecnologias do eu", as quais permitem:

(...) que os indivíduos efetuem, por conta própria ou com a ajuda de outros, certo número de operações sobre seu corpo e sua alma, pensamentos, conduta ou qualquer forma de ser, obtendo, assim, uma transformação de si mesmos, com o fim de alcançar certo estado de felicidade, pureza, sabedoria ou imortalidade. (FOUCAULT, 2001b, p. 48).

Em outro estudo, o filósofo também explicita seu entendimento das "técnicas de si", que para ele seriam procedimentos: "pressupostos ou prescritos aos indivíduos para fixar sua identidade, mantê-la ou transformá-la em função de determinados fins, e isso graças a relações de domínio de si sobre si ou de conhecimento de si por si" (FOUCAULT, 1997, p. 109).Tais procedimentos estão centralmente implicados nos processos de subjetivação, na constituição do sujeito. Como escreve Larrosa (2000, p. 56): "O sujeito, sua história e sua constituição como objeto para si mesmo, seriam (...) inseparáveis das tecnologias do eu". Neste mesmo estudo, o autor examina formas pelas quais as práticas pedagógicas estão implicadas na constituição do sujeito, argumentando que tais práticas constroem e medeiam a relação do sujeito consigo mesmo (a relação na qual se estabelece, se regula e se modifica a experiência que a pessoa tem de si mesma).

Esta experiência de si compreende o resultado de um complexo processo histórico de fabricação no qual se entrecruzam "os discursos que definem a verdade do sujeito, as práticas que regulam seu comportamento e as formas de subjetividade nas quais se constitui sua própria interioridade" (LARROSA, 2000, p. 43). É, portanto, historicamente constituída, sendo "aquilo a respeito do qual o sujeito se oferece seu próprio ser quando se observa, se decifra, se interpreta, se descreve, se julga, se narra, se domina, quando faz determinadas coisas consigo mesmo, etc." (ibidem, p. 43) Entre tais "determinadas coisas" poderiam ser incluídas as atividades em que os alunos do PEA são incitados a refletirem sobre seu desempenho escolar, tomando como foco o seu modo de participar das tarefas escolares e o porquê do erro ou acerto. Como diz Larrosa (ibidem, p. 69): "É contando histórias, nossas próprias histórias, o que nos acontece e o sentido que damos ao que nos acontece, que nos damos a nós próprios uma identidade no tempo".

Sendo a experiência de si histórica e culturalmente contingente, é também algo que deve ser transmitido e aprendido, ou seja, cada cultura transmite modos de experiência de si que são aprendidos por cada um de seus membros. Por isto, a instituição escolar (que em nossa sociedade está centralmente ocupada com os processos de socialização e transmissão cultural) além de construir e transmitir uma experiência "objetiva" do mundo exterior, constrói e transmite também "a experiência que as pessoas têm de si mesmas e dos outros como "sujeitos"” (LARROSA, 2000, p. 45). É nesta perspectiva que o autor argumenta que a pedagogia não pode ser considerada como um espaço neutro, ou como um local que gera a melhoria do autoconhecimento e da autonomia, mas como produzindo formas de experiência de si nas quais "os indivíduos podem se tornar sujeitos de um modo particular" (ibidem, p. 57). Em outro estudo (KNIJNIK e WANDERER, 2005), ao analisarmos o processo de avaliação realizado com futuras professoras em torno da 
prática de estágio docente que realizaram, como parte curricular de seu Curso de Pedagogia, mostramos, a partir de material empírico gerado na pesquisa, os modos pelos quais elas se tornaram professoras (de matemática) de um modo particular. Esse modo diz que é importante gostar da matemática e fazer com que seus alunos dela também gostem, que é relevante tornar as aulas de matemática mais agradáveis e prazerosas e que a boa professora é aquela que reflete sobre sua própria prática.

Larrosa (2000) escreve sobre a gramática que aprendemos nos processos educativos em que nos narramos, nos julgamos, refletimos sobre nós mesmos, ao se referir a uma atividade pedagógica na qual as crianças eram incitadas a responder, individualmente, questões a respeito de si: seu comportamento, o que gostavam de fazer, quem gostariam de ser etc. Relata que após um primeiro momento de trabalho individual, as crianças foram organizadas em duplas, para discutir suas respostas e, posteriormente, cada dupla construiu murais, expressando suas diferenças e semelhanças. Pondo "sob suspeita" esta atividade, o autor salienta que nela as crianças aprenderam uma gramática para a sua autointerpretação e para a interrogação pessoal do outro: as diferenças que marcam cada um de nós, que tais diferenças podem ser apreendidas e julgadas, que "é possível mudar coisas em si mesmo para ser melhor e (...) que é possível comunicar o próprio modo de ser, que é possível viver junto, apesar das diferenças, dadas certas atitudes de compreensão, respeito e tolerância, etc" (ibidem, p. 47). Neste processo, as crianças aprendem, segundo o autor, a "realizar um certo tipo de jogo, de acordo com certas regras. Aprendem o que significa o jogo e como jogá-lo legitimamente" (ibidem, p. 47). Seguindo as ideias do autor e os excertos até aqui reunidos podemos dizer que nesse jogo produzido pelas práticas da auto avaliação propostas pelo PEA as crianças aprendem a avaliar seu próprio desempenho em Matemática a partir de três regras: o seu nível de compreensão (do conhecimento matemático), sua participação em tarefas e o porquê do seu erro.

Ao examinar a terceira dessas regras constatamos que nos documentos é recomendado aos docentes a análise do erro, uma vez que "possibilita uma compreensão mais clara das dificuldades da criança, permitindo ao professor uma intervenção pedagógica correta e oportuna. Uma dificuldade apresentada pelo aluno é sinal de alerta e deve ser considerada" (BRASIL, 2010c, p. 15).Aqui nos interessa evidenciar que, mais uma vez, os alunos passam a ser objeto do olhar constante do professor. "A observação mais atenta e a pesquisa das causas de tal dificuldade oferecem subsídios ao professor para um diagnóstico mais preciso" (ibidem, p. 15). Ainda mais, é essa observação que possibilita que o professor identifique "indícios da necessidade de revisão e reorganização das atividades em sala de aula" (ibidem, p. 15).

Foi na última década do século passado que houve uma incidência de estudos sobre o papel "terapêutico" do erro na aprendizagem da matemática (BRAY e SANTAGATA, 2013; BORASI, 1994; CURY, 2012). Documentos oficiais do Ministério da Educação e Cultura (como os PCN's) também tratam dessa questão, que se tornou uma "verdade" no campo da Educação Matemática. Afastando-nos das formulações sobre o erro já exaustivamente desenvolvidas, nosso interesse se volta para o exame do que é tomado (de modo naturalizado) como "erro" na disciplina Matemática. Nos parece oportuno, aqui, voltar aos ensinamentos de Foucault, precisamente à discussão empreendida por ele sobre a disciplina como procedimento interno de controle do discurso. Para o filósofo, a disciplina "constitui uma espécie de sistema anônimo à disposição de quem quer ou pode servir-se dele, sem que seu sentido ou sua validade estejam ligados a quem sucedeu ser seu inventor" (FOUCAULT, 2001a, p. 30). Também:

Não persegue a repetição; melhor, exige a novidade, a geração de proposições ainda não formuladas. A disciplina determina as condições que deve cumprir uma proposição determinada para entrar no campo do verdadeiro: estabelece de que objetos se deve falar, que instrumentos conceituais ou técnicas devem ser utilizadas, em que horizonte teórico se deve inscrever [a proposição] (CASTRO, 2004, p. 86).

Mas as proposições ainda não formuladas que serão geradas não podem ser quaisquer. "Em toda disciplina há objetos, métodos, proposições verdadeiras, regras, definições, técnicas e instrumentos à disposição de seus possíveis participantes" (DIAZ, 2005, p. 80) e proposições que não estejam alinhadas a isso são consideradas espúrias, e, portanto, devem ser excluídas da disciplina, "repel[idas], para fora de suas margens" (FOUCAULT, 2001a, p. 33). O filósofo explica esse ponto: "Uma disciplina não é a soma de tudo que pode ser dito de verdadeiro sobre alguma coisa; não é nem mesmo o conjunto de tudo o que pode ser aceito, a propósito de um mesmo dado, em virtude de um princípio de coerência ou de sistematicidade" (ibidem, p. 31). Se, para Foucault, "a medicina não é constituída de tudo o que se pode dizer de verdadeiro sobre a doença" (ibidem, p. 31), o mesmo valendo para a Botânica, no que diz respeito às plantas, poderíamos pensar em estender essa posição para a matemática e, parafraseando o filósofo, considerar, que a [matemática] não pode ser definida pela soma de todas as verdades que concernem aos jogos de linguagem envolvendo quantificações (como, por exemplo, calcular áreas de superfícies, que foi discutido em um estudo (KNIJNIK, 2007) com camponeses Sem Terra do sul do país). 
Assim, por exemplo, diríamos que a matemática escolar não reúne todos os jogos de linguagem de calcular áreas, "repelindo para fora de suas margens" jogos como os de cubar a terra da matemática camponesa (KNIJNIK, 2007), com suas regras específicas, diferentes das regras do formalismo e abstração que conformam a gramática da matemática escolar. Os jogos de linguagem constitutivos das práticas de cubação da terra (KNIJNIK, 2006) produzem resultados "aproximados" (em maior ou menor grau) do resultado preciso da matemática (acadêmica), resultados inexatos. Mas, como aponta Wittgenstein (2004) no aforismo 88 de Investigações: inexato não significa sem utilidade. O filósofo escreve:

\begin{abstract}
'Inexato' é, na verdade, uma censura e 'exato' é um elogio. E isso quer dizer: o inexato não atinge o seu alvo tão perfeitamente como o mais exato. Depende, pois, do que chamamos 'o alvo'. Sou inexato se não indico com precisão métrica a que distância o sol está de nós, e se não indico ao carpinteiro com precisão milimétrica a largura da mesa? Não está previsto um ideal de precisão, nem sabemos que ideia fazer disso - a não se que você mesmo estipulo o que deve ser denominado assim. Mas vai ser difícil para você encontrar uma tal estipulação, uma que o satisfaça (2004, p. 76).
\end{abstract}

Os resultados inexatos - mas úteis aos camponeses, por exemplo - são considerados pela matemática escolar, muitas vezes, como "erros". Mas, como escreve Foucault, "talvez não haja erros em sentido estrito porque o erro só pode surgir e ser decidido no interior de uma prática definida" (2001a, p. 33). Os jogos de linguagem de cubar a terra, quando examinados na contingência da forma de vida camponesa Sem Terra a que estão associados, não apresentam erro algum "no sentido estrito". Por serem úteis para a tomada de decisão sobre práticas de cultivo e, ademais, fáceis de serem usados, os camponeses não desqualificam esses seus saberes regionais.

Como apontam as reflexões acima, a própria questão do que pode/deve ser considerado como erro precisa ser problematizada. Nos documentos do PEA isso está ausente, reforçando o que anteriormente discutimos quanto à ausência, em tais documentos, de teorizações que ofereçam subsídios teóricos para as orientações dadas pelo Programa (KNIJNIK e WANDERER, 2013).

\section{CONSIDERAÇÕES FINAIS}

Mesmo que este texto chegue, agora, a seu final, estamos cientes de que ele não esgotou as possibilidades de análise de um programa da envergadura do PEA. Ao tomar como foco empírico da investigação seus documentos (em especial, aqueles diretamente relacionados à área da Matemática), colocamos nosso olhar sobre a avaliação escolar e operarmos sobre os mesmos de modo a produzir significados ao que ali está expresso. Com isso, buscamos mostrar como a avaliação proposta pelo PEA, entre outras tantas coisas que sobre ela poderiam ser ditas, se constitui em um mecanismo de poder-saber, que atua sobre professores e estudantes das classes multisseriadas do campo, no país. Ao examinála nessa dimensão analítica, tivemos o cuidado de evitar juízos de valor que, ao fim e ao cabo, nos conduzissem a categorizações do tipo "certo" ou "errado" sobre o indicado nos documentos do Programa no que diz respeito aos processos avaliativos (em matemática). Assim, nossa intenção não foi a de criticar as orientações dadas aos professores, buscando substituí-las por outras que, essas sim, seriam mais efetivas.

Caberia indagar, então, sobre a relevância de um estudo como o aqui apresentado. A resposta a essa indagação pode ser dada a partir das formulações de Foucault sobre a noção de crítica e as reflexões de Veiga-Neto a respeito do que o autor chamou hipercrítica. Para o filósofo francês, "a crítica é o movimento pelo qual o sujeito se dá o direito de interrogar a verdade sobre seus efeitos de poder e o poder sobre seus discursos de verdade (...)" (FOUCAULT, 1990, p. 5). Neste estudo, poderíamos dizer que exercitamos a crítica na medida em que tratamos de interrogar as verdades que constituem o discurso do PEA sobre a avaliação. Inspiradas nas posições de Foucault, buscamos exercitar aquilo que ele chamou de "arte da inservidão voluntária, aquela da indocilidade refletida" (ibidem, p. 5). Se o resultado do estudo contemplou essa arte, podemos pensar que ele contribui para o campo educacional. Isso porque, para o filósofo "a crítica (e a crítica radical) é absolutamente indispensável para toda transformação" que se pretenda não "apenas uma transformação superficial” (FOUCAULT, 2006, p. 3).

Por sua vez, a noção de hipercrítica, como concebida por Veiga-Neto (2006) e discutida em profundidade por Veiga-Neto e Lopes (2010), pode ser pensada como "uma modalidade de crítica" (ibidem, p. 14) que nos permite "pensar de outro modo" (ibidem, p. 13), "um tipo de desconstrucionismo que faz da crítica uma prática permanente e intransigente até consigo mesma, de modo a estranhar e desfamiliarizar o que parecia tranquilo e acordado entre todos". É ela que poderá nos abrir possibilidades para que se possa "pensar de outro modo" a avaliação, a educação matemática e, em particular, a discussão aqui apresentada.

\section{REFERÊNCIAS}

ALVES, Iane; MONTEIRO, Carlos Eduardo. Escola Ativa: analisando os Guias de Aprendizagem de Matemática de $1^{\mathrm{a}}$ a $4^{a}$ séries. TCC - Revista de divulgação científica do curso de Pedagogia, Belém, v. 2, p. 1-24, 2011. 
ANDRADE, Alenis C. Avaliação em larga escala, Prova Brasil: perspectiva da gestão democrática. Anais do $\mathbf{X}$ Congresso Nacional de Educação - EDUCERE. Curitiba, PUC/PR, 2011.

ARAGÃO, Márcia Cristina da Cruz. A educação do campo e o Programa Escola Ativa: uma análise do Programa em escolas sergipanas. Dissertação (Mestrado em Educação) Universidade Federal de Sergipe, São Cristóvão, 2011.

ARNOLD, Delci K. Dificuldade de aprendizagem: o estado de corrigibilidade na escola para todos. Dissertação (Mestrado em Educação) - Universidade do Vale do Rio dos Sinos, São Leopoldo, 2006.

BARRIGA, Angel D. El examen: textos para su historia y debate. México: Plaza y Valdes, 1993.

BECKER, Fernanda da Rosa. Avaliação educacional em larga escala: a experiência brasileira. Revista Ibero americana de Educación/Revista Ibero-americana de Educação, Centro de Altos Estudios Universitarios de la Organización de Estados Ibero-americanos (CAEU/OEI), n. 53, v. 1, p. 1-11, jun. 2010.

BORASI, Raffaella. Capitalizing on Errors as "Springboards for Inquiry": A Teaching Experiment. Journal for Research in Mathematics Education, v. 25, n. 2, p. 166-208, 1994.

BRASIL, Ministério da Educação. Secretaria de Educação Continuada, Alfabetização e Diversidade. Projeto base (Programa Escola Ativa). Brasília: SECAD/MEC, 2010a.

- Caderno de orientações pedagógicas para formação de educadoras e educadores (Programa Escola Ativa). Brasília: SECAD/MEC, 2010b.

Caderno do educador: Matemática (Programa Escola Ativa). Brasília: SECAD/MEC, 2010c.

BRAY, Wendy; SANTAGATA, Rossella. Developing Teaching Capacity for Making Productive Use of Mathematical Errors. Association of Mathematics Teacher Educators, Annual Meeting, Orlando/Florida, 2013.

BUJES, Maria Isabel Edelweiss. Infância e maquinarias. Rio de Janeiro: DP\&A, 2002.

BURIASCO, Regina L; SOARES, Maria Teresa C. Avaliação do rendimento em Matemática nas escolas do Paraná: estudo descritivo da prova da $4^{\mathrm{a}}$ e $8^{\mathrm{a}}$ séries do ensino fundamental. Estudos em Avaliação Educacional, São Paulo, v. 18, n. 38, p. 85-110, set./dez. 2007.

CARVALHO, Luis Miguel. Governando a educação pelo espelho do perito: uma análise do PISA como instrumento de regulação. Educação e Sociedade, Campinas, v. 30, n. 109, p. 1009-1036, set./dez. 2009.

CARVALHO, Rodrigo Saballa de. Pareceres descritivos: Histórias de saber, poder e verdade sobre os/as infantis. Anais do VI Colóquio sobre Questões Curriculares, II Colóquio Lusobrasileiro sobre Questões Curriculares. Currículo: Pensar, Inventar, Diferir. Rio de Janeiro, 2004.

CASTRO, Edgardo. Vocabulário de Foucault. Belo Horizonte: Autêntica, 2004.

CORAZZA, Sandra M. Currículo e política cultural da avaliação. Educação \& Realidade, Porto Alegre, v. 20, n. 2, p. 47-59, 1995.
CURY, Helena N. Pesquisas em ensino de ciências e matemática, relacionadas com erros: uma investigação sobre seus objetivos. Educação Matemática Pesquisa (Online), São Paulo, v. 14, p. 237-256, 2012.

DELEUZE, Gilles. Foucault. São Paulo: Brasiliense, 2005.

DÍAZ, Esther. La filosofía de Michel Foucault. Buenos Aires: Biblos, 2005.

DREYFUS, Hubert; RABINOW, Paul.Michel Foucault. Uma trajetória filosófica. Rio de Janeiro: Forense Universitária, 1995.

ESTEBAN, Maria Teresa. O que sabe quem erra? Reflexões sobre avaliação e fracasso escolar. Rio de Janeiro: DP\&A, 2002.

FOUCAULT, Michel. Est-ildonc important de penser? In: FOUCAULT, Michel. Ditsetécrits IV (1980-1988). Paris: Gallimard, 2006. p. 178-182. Disponível em: $<$ http://portalgens. com.br/portal/images/stories/pdf/pensar.pdf $>$. Acesso em: 17 nov. 2013.

Arqueologia do saber. Rio de Janeiro: Forense Universitária, 2002a.

Vigiar e punir: nascimento da prisão. Petrópolis: Vozes, 2002 b.

A ordem do discurso. São Paulo: Loyola, 2001a.

História da sSexualidade - o uso dos prazeres. Rio de Janeiro: Graal, 2001b.

Resumo dos cursos do Collège de France (19701982). Rio de Janeiro: Jorge Zahar Ed., 1997.

Qu'est-ce que la critique? Critique et Aufklärung. Bulletin de La Société française de philosophie,v. 82, n. 2, p. 35-63, 1990 (Conferência proferida em 27 de maio de 1978).

GONÇALVES, Gustavo B. Programa Escola Ativa: educação do campo e trabalho docente. Tese (Doutorado em Políticas Públicas e Formação Humana) - Universidade do Estado do Rio de Janeiro, Rio de Janeiro, 2009.

HOFFMANN, Jussara. Avaliação mediadora: uma prática em construção da pré-escola à Universidade. Porto Alegre: Mediação, 1996.

JUNGES, Débora de Lima Velho. Família, escola e educação matemática: um estudo em localidade de colonização alemã do Vale do Rio dos Sinos - RS. Dissertação (Mestrado em Educação) - Universidade do Vale do Rio dos Sinos, São Leopoldo, 2012.

KNIJNIK, Gelsa. Educação matemática, culturas e conhecimento na luta pela terra. Santa Cruz do Sul: EDUNISC, 2006.

Mathematics education and the Brazilian Landless Movement: three different mathematics in the context of the struggle for social justice. Philosophy of Mathematics Education Journal, v. 21, p. 1-18, 2007.

KNIJNIK, Gelsa; WANDERER, Fernanda. Programa Escola Ativa, escolas multisseriadas do campo e educação matemática. Educação e Pesquisa (USP), v. 39, p. 211-225, 2013.

Narrar-se, descrever-se, avaliar-se: a experiência de si produzida em uma atividade curricular na formação docente. Anais do IV Congresso Internacional de Educação. São Leopoldo: Universidade do Vale do Rio dos Sinos, 2005. 
LARROSA, Jorge. Tecnologias do eu e educação. In: SILVA, Tomaz Tadeu da (Org.). O sujeito da educação. Estudos foucaultianos. Petrópolis: Vozes, 2000. p. 35-86.

LUCKESI, Cipriano Carlos. Avaliação da aprendizagem na escola: reelaborando conceitos e recriando a prática. Salvador: Malabares Comunicação e Eventos, 2005.

MACHADO, Ledo V. Avaliação de larga escala e proficiência em Matemática. Dissertação (Mestrado em Ensino de Matemática - Universidade Federal do Rio de Janeiro, Rio de Janeiro, 2010.

MATOS, Cleide Carvalho de. Concepções, princípios e organização do currículo no Projeto Escola Ativa. Dissertação (Mestrado em Educação) - Universidade Federal do Pará, Belém, 2010.

MOREIRA, Vilson A. Educação do campo e docência no contexto da agricultura familiar: o Programa Escola Ativa (PEA/MEC) no município de Salinas - MG. Tese (Doutorado em Desenvolvimento Rural) - Universidade Federal do Rio Grande do Sul, Porto Alegre, 2013.

MORGAN, Candia. Assessment in mathematics education: A critical social research perspective. Actas do IX Seminário de Investigação em Educação Matemática. Guimarães: Associação de Professores de Matemática, p.5-23, 1999. Disponível em: <http://www.academia.edu/443152/Assessment_ in_mathematics_education_A_critical_social_research_ perspective>. Acesso em: 17 nov. 2013.

MOTA, Maria Océlia. Avaliações externas e seus impactos nas práticas pedagógicas de alfabetização: Percepções e visões preliminaries. Anais do XVI ENDIPE - Encontro Nacional de Didática e Práticas de Ensino. Campinas: UNICAMP, 2012.

PETRONZELLI, Vela Lucia L. Políticas públicas de avaliação: a literacia matemática e o PISA. Anais do XI ENEM - Encontro Nacional de Educação Matemática. Educação Matemática: Retrospectivas e perspectivas. Curitiba: PUC/PR, 2013

RIBEIRO, Marlene. Educação do campo e Escola Ativa: contradições na política educacional no Brasil. Educação em Revista, Marília, v. 12, n. 2, p. 23-40, 2011.

STACEY, Kaye; WILIAM, Dylan.Technology and assessment in Mathematics. In: CLEMENTS, M. et al. (Org.). Third International Handbook of Mathematics Education. New York: Springer, p. 721-752, 2013.
VASCONCELlOS, Celso. Avaliação. Concepção dialéticalibertadora do processo de avaliação escolar. São Paulo: Libertad, 2007.

VEIGA-NETO, Alfredo. Dominação, violência, poder e educação escolar em tempos de Império. In: RAGO, Margareth; VEIGA-NETO, Alfredo (Org.). Figuras de Foucault. Belo Horizonte: Autêntica, 2006. p.13-38.

Foucault \& Educação. Belo Horizonte: Autêntica, 2003.

VEIGA-NETO, Alfredo; LOPES, Maura Corcini. Para pensar de outros modos a modernidade pedagógica. ETD - Educação Temática Digital, Campinas, v. 12, n. 1, p. 147-166, 2010.

WANDERER, Fernanda; KNIJNIK, Gelsa. O discurso da avaliação do Programa Escola Ativa no âmbito da educação (matemática). Anais do III Congresso Internacional de Avaliação - VIII Congresso Internacional de Educação. São Leopoldo: Casa Leria, 2013. p. 1-13.

WITTGENSTEIN, Ludwig. Investigações filosóficas. Petrópolis: Vozes, 2004.

\section{Notas}

1 No site do MEC (acessado em 02/11/2013), não há indicações formais de que o PEA será substituído pelo "Escola da Terra". Ambos programas estão ali disponibilizados.

2 Informações disponíveis no site do MEC (acesso em 02/11/2013) destacam que o programa Escola da Terra, cujas ações estão descritas na Portaria $\mathrm{n}^{\circ}$ 579, de 3 de julho de 2013, do Ministério da Educação, tem por objetivo "promover a melhoria das condições de acesso, permanência e aprendizagem dos estudantes do campo e quilombolas em suas comunidades, por meio do apoio à formação de professores que atuam nas turmas dos anos iniciais do ensino fundamental compostas por estudantes de variadas idades, e em escolas de comunidades quilombolas, fortalecendo a escola como espaço de vivência social e cultural". Para isso, o Programa prevê a realização de quatro ações: formação continuada de professores (e de tutores que desempenharão o papel de assessores pedagógicos); produção e distribuição de materiais pedagógicos e didáticos; gestão; monitoramento e avaliação.

3 O Censo Escolar de 2009 indica que, no Brasil, há em torno de 83 mil escolas denominadas rurais, sendo que 39 mil possuem classes multisseriadas, as quais atendem a 1 milhão e 300 mil alunos do ensino fundamental.

${ }^{4}$ Duas obras do filósofo são particularmente referenciadas na discussão dessa perspectiva: Arqueologia do Saber (FOUCAULT, 2002a) e $A$ ordem do discurso (FOUCAULT, 2001a). Foge ao escopo deste texto aprofundar sua discussão, realizada por autores como Veiga-Neto (2003), Bujes (2002) e Knijnik e Wanderer (2013).

Artigo recebido em novembro 2013.

Aprovado em dezembro 2013. 